\title{
Effect of Ethynodiol Diacetate and a Combination-Type Oral Contraceptive Compound on Carbohydrate Metabolism
}

\author{
II. One Year Intravenous Glucose Tolerance Study
}

\section{J. A. Goldman}

Department of Obstetrics-Gynaecology, Hasharon Hospital, Petah-Tikva and Tel-Aviv University Medical School, Petah-Tikva, Israel

\begin{abstract}
Summary. Blood glucose and plasma insulin levels were measured in two groups of women, following one year of oral contraceptive therapy of different types. There were no significant differences from pretreatment glucose and insulin values in the first group of women (on ethynodiol diacetate). In the second group (on norethynodrel and mestranol), there was a significant elevation of mean blood glucose levels in the fasting state and at all times of an i. v. glucose tolerance test. Furthermore, a statistically significant alteration in plasma insulin was observed at all times of the test (except at $120 \mathrm{~min}$ ). Patients participating in this study will continue this treatment, and results of carbohydrate metabolism monitoring will be reported after 2 years of therapy.
\end{abstract}

Key words: Oral contraceptives, carbohydrate metabolism, glucose tolerance, contraceptive steroids, ethynodiol diacetate.

Spellacy [1] and Beck [2] have recently reviewed the effect of oral contraceptives on carbohydrate metabolism.

In a previous report [3] I described a prospective study done in normal, non-diabetic women attending our family-planning clinic, in order to evaluate the change in blood glucose and plasma insulin levels under the effect of oral contraceptives of different types, after a six month period.

The present investigation reports the results of a one-year study of the effect of ethynodiol diacetate and norethynodrel-mestranol (ENOVID) on blood glucose and plasma insulin.

\section{Material and Methods}

Included in this study were women attending the family-planning clinic of the Beilinson Hospital. Patients with a family history of diabetes or history suggestive of prediabetes or latent diabetes were excluded.

Two groups of women participated:

\section{Group 1}

Comprised thirty-six nonpregnant, parous women. Their ages ranged from 21 to 35 years, with a mean of 29 years.

\section{Group 2}

Comprised thirty-six nonpregnant, parous women. Their ages ranged from 22 to 33 years, with a mean of 28 years.

A comparison was made of the characteristics of both groups. No statistical difference was found when age, weight, height and parity were compared. None of these women was on any other steroid therapy, or was less than 6 months after a pregnancy.

The intravenous glucose tolerance test (iv GTT) was performed as previously described [4]. Following the first test, each subject in the first group received one tablet of ethynodiol diacetate ${ }^{1}(0.5 \mathrm{mg})$ daily for 12 months. Each subject in the second group was instructed to take 21 tablets of Enovid ${ }^{2}$, a combination-type oral contraceptive containing norethynodrel and mestranol, each month for a total of 12 months. Since each patient was tested before and after taking the contraceptive drug, she served as her own

\footnotetext{
1 Ethynodiol diacetate, G.D. Searle \& Co. England

2 Enovid, G.D. Searle \& Co. Chicago, U.S. A.
} 
control. The correlated pairs were evaluated statistically by means of Student's $t$ test. A second iv GTT was performed on each patient, on one of the last days of treatment.

\section{Results}

Mean values for blood glucose and plasma insulin during an intravenous glucose tolerance test are shown in Tables 1 and 2.

\section{Glucose}

The mean values before and after oral contraceptive treatment with ethynodiol diacetate did not differ significantly at any time during the test. The mean values before and after oral contraceptive treatment with norethynodrel-mestranol differed significantly at all times of the iv GTT.

\section{Insulin}

The mean values before and after oral contraceptive treatment with ethynodiol diacetate did not differ significantly at any time during the test. The mean values before and after Enovid therapy showed a significant difference at all times during the iv GTT.

\section{Discussion}

Vast experience has accumulated over recent years on the effects of different steroids used for fertility control. Reviews of alterations in carbohydrate metabolism in women using oral contraceptives have suggested that these steroids differ significantly in their effects, which are most probably related to type, duration of use, dosage and amounts and relative proportions of estrogen and progesterone in the oral contraceptive employed. Of no less importance is the age of the recipient, and her predisposition to metabolic disease $[1,2]$.

While the diabetogenic effect of estrogen-progesterone compounds has now been well established, the effect of progesterone alone contraceptive steroids, also designed as "minipills", has not definitely been clarified. It has been suggested that metabolic change may depend, among other things, upon the type of progestogen from which the "pills" are derived [1].

Reports on some of these progestogens are controversial. While some demonstrate impairment of glucose tolerance under the influence of this drug [5, $6,7]$, others deny the occurrence of alterations in carbohydrate metabolism [8].
Table 1. Statistical comparison (Student's t test) of blood glucose and plasma immunoreactive insulin levels during iv GTT in subjects before and after 12 months of oral contraceptive therapy with ethynodiol diacetate, $0.5 \mathrm{mg}(\mathrm{N}=36)$

\begin{tabular}{|c|c|c|c|c|c|}
\hline \multicolumn{6}{|c|}{ a) Blood glucose levels $(\mathrm{mg} / 100 \mathrm{ml})$} \\
\hline & FBS & $15^{\prime}$ & $30^{\prime}$ & $60^{\prime}$ & $120^{\prime}$ \\
\hline \multicolumn{6}{|c|}{ Before therapy } \\
\hline Mean & 79.2 & 201.4 & 171.0 & 93.0 & 80.0 \\
\hline $\begin{array}{l} \pm \mathrm{S} . \mathrm{D} . \\
\text { After therapy }\end{array}$ & 6.4 & 15.9 & 12.6 & 4.9 & 5.3 \\
\hline Mean & 78.1 & 200.3 & 171.0 & 93.4 & 79.6 \\
\hline \pm S.D. & 7.1 & 15.0 & 12.7 & 5.0 & 6.0 \\
\hline $\mathrm{t}$ & 0.69 & 0.30 & 0.00 & 0.34 & 0.30 \\
\hline $\mathrm{P}$ & N.S. ${ }^{a}$ & N.S. & N.S. & N.S. & N.S. \\
\hline
\end{tabular}

b) Plasma insulin levels $(\mu \mathrm{u} / \mathrm{ml})$

\begin{tabular}{|c|c|c|c|c|c|}
\hline & FPI & $15^{\prime}$ & $30^{\prime}$ & $60^{\prime}$ & $120^{\prime}$ \\
\hline \multicolumn{6}{|c|}{ Before therapy } \\
\hline Mean & 18.0 & 75.0 & 36.0 & 20.4 & 19.0 \\
\hline $\begin{array}{l} \pm \text { S. D. } \\
\text { After therapy }\end{array}$ & 4.5 & 15.8 & 9.0 & 4.7 & 4.5 \\
\hline Mean & 16.0 & 71.7 & 35.0 & 20.0 & 17.8 \\
\hline \pm S.D. & 5.0 & 16.2 & 11.2 & 6.0 & 5.6 \\
\hline $\mathrm{t}$ & 1.75 & 0.85 & 0.40 & 0.34 & 0.98 \\
\hline$P$ & N.S. & N.S. & N.S. & N.S. & N.S. \\
\hline
\end{tabular}

${ }^{\mathrm{a}} \mathrm{N} . \mathrm{S} .=$ nonsignificant

Table 2. Blood glucose and plasma immunoreactive insulin levels during iv GTT before and after 12 months of oral contraceptive therapy with a combination-type compound (Enovid) $(\mathrm{N}=36)$

\begin{tabular}{|c|c|c|c|c|c|}
\hline \multicolumn{6}{|c|}{ a) Blood glucose levels (mg/100 ml) } \\
\hline & FBS & $15^{\prime}$ & $30^{\prime}$ & $60^{\prime}$ & $120^{\prime}$ \\
\hline \multicolumn{6}{|c|}{ Before therapy } \\
\hline Mean & 82.0 & 190.0 & 172.2 & 90.5 & 78.7 \\
\hline $\begin{array}{l} \pm \text { S. D. } \\
\text { After therapy }\end{array}$ & 12.2 & 11.9 & 16.6 & 8.6 & 9.7 \\
\hline Mean & 93.3 & 198.6 & 183.0 & 98.3 & 86.4 \\
\hline \pm S.D. & 13.8 & 18.3 & 18.2 & 13.5 & 11.1 \\
\hline t & 3.68 & 2.36 & 2.63 & 2.93 & 3.96 \\
\hline \multirow[t]{2}{*}{$P$} & $S^{a}$ & $S$ & $S$ & $S$ & $S$ \\
\hline & $<0.01$ & $<0.02$ & $<0.02$ & $<0.02$ & $<0.001$ \\
\hline
\end{tabular}

b) Plasma insulin levels $(\mu \mathrm{u} / \mathrm{ml})$

\begin{tabular}{|c|c|c|c|c|c|}
\hline & FPI & $15^{\prime}$ & $30^{\prime}$ & $60^{\prime}$ & $120^{\prime}$ \\
\hline \multicolumn{6}{|c|}{ Before therapy } \\
\hline Mean & 21.0 & 87.6 & 34.0 & 20.0 & 17.0 \\
\hline $\begin{array}{l} \pm \text { S. D. } \\
\text { After th }\end{array}$ & 5.0 & 15.8 & 10.4 & 4.8 & 4.9 \\
\hline Mean & 28.0 & 99.0 & 41.0 & 24.0 & 16.5 \\
\hline \pm S.D. & 8.4 & 14.8 & 8.9 & 5.5 & 4.3 \\
\hline t & 4.31 & 3.16 & 3.08 & 3.29 & 0.46 \\
\hline \multirow[t]{2}{*}{$P$} & $S$ & $S$ & $S$ & $\begin{array}{l}S \\
\downarrow\end{array}$ & N.S. \\
\hline & $<0.01$ & $<0.01$ & $<0.02$ & $<0.02$ & \\
\hline
\end{tabular}

${ }^{a} \mathrm{~S}=$ significant 
There is conflicting evidence concerning ethynodiol diacetate, a nortestosterone derivative, and its effect on carbohydrate metabolism. While Spellacy et al. [9] observed deterioration of oral glucose tolerance in $13 \%$ of normal women after 6 months' treatment with the steroid ethynodiol diacetate, and an increase in mean plasma insulin concentration, we were unable to confirm these findings. We investigated blood glucose and plasma insulin in women after the short-term use of ethynodiol diacetate as an oral contraceptive $[10]$, and observed no consistent changes in carbohydrate metabolism.

In a recent comparative study of the effect of ethynodiol diacetate and a combination of norethynodrel and mestranol in normal, nonpregnant women, on blood glucose and plasma insulin over a period of 6 months, no diabetogenic effect of the former was elicited, while the latter did cause consistent impairment of glucose metabolism, but did not affect insulin levels [3].

In the present study no significant alterations were found in subjects taking the ethynodiol diacetate oral contraceptive. In women on Enovid, a statistically significant change was shown in blood glucose levels, both in the fasting state and at all times of an iv glucose tolerance test. Furthermore, a statistically significant alteration was demonstrated in plasma insulin levels only at $60 \mathrm{~min}$ following an iv load of glucose. We were unable to explain the lack of insulin increase at other times of the iv GTT, corresponding to blood glucose alterations. Our findings demonstrate again an impairment of carbohydrate metabolism under the effect of combination-type birth control pills. Moreover, the fact that ethynodiol diacetate produces no measurable effect on glucose tolerance and plasma insulin in women taking this drug for up to 12 months, should no doubt influence the choice of oral contraceptives used for long-term contraception.

In order to evaluate long-term effects of these types of oral contraceptive compounds, we intend to continue our follow-up of both study-groups.

Acknowledgements. We are grateful to G. D. Searle \& Co., England, for supplying ethynodiol diacetate.
The technical assistance of Mrs. Shoshana Mannheimer, and statistical analysis by Mrs.ZeliksonSinger and Mrs. Rivka Resnik is appreciated.

\section{References}

1. Spellacy, W. N.: A review of carbohydrate metabolism and the oral contraceptives. Am. J. Obstet. Gynecol. 104, 448-469 (1969)

2. Beck, P.: Contraceptive steroids: modifications of carbohydrate and lipid metabolism. Metabolism 22, 841-856 (1973)

3. Goldman, J.A.: Effect of ethynodiol diacetate and combination-type oral contraceptive compounds on carbohydrate metabolism. I. Six month intravenous glucose tolerance study. Diabetologia 11, 45-48 (1975)

4. Goldman, J. A., Eckerling, B.: Effect of a progestogen oral contraceptive compound on carbohydrate metabolism. Isr. J. Med. Sci. 8, 1724-1727 (1972)

5. Spellacy, W. N., Buhi, W.C., Birk, S.A., McCreary, S.A.: Metabolic studies in women taking norethindrone for 6 months' time (measurements of blood glucose, insulin, and triglyceride concentrations). Fertil. Steril. 24, 419-425 (1973)

6. Spellacy, W.N., McLeod, A.G.W., Buhi, W.C., Birk, S. A., McCreary, S. A.: Medroxy-progesterone acetate and carbohydrate metabolism. Measurement of glucose, insulin and growth hormone during 6 months' time. Fertil. Steril. 21, 457-463 (1970)

7. Spellacy, W. N., McLeod, A. G.W., Buhi, W.C., Birk, S.A., McCreary, S. A.: The effect of medroxy-progesterone acetate on carbohydrate metabolism: measurement of glucose, insulin and growth hormone after 12 months' use. Fertil. Steril. 23, 239-244 (1972)

8. Spellacy, W. N., Newton, R. E., Buhi, W. C., Birk, S. A.: Carbohydrate and lipid studies during six months treatment with megestrol acetate. Measurements of blood glucose, insulin, growth hormone, and triglycerides. Am.J. Obstet. Gynecol. 116, 1074-1078 (1973)

9. Spellacy, W.N., Buhi, W.C., Birk, S. A.: The effect of the progesterone ethynodiol diacetate on glucose, insulin, and growth hormone after 6 months treatment. Acta Endocrinol. (Kbh.) 70, 373 (1972)

10. Goldman, J. A., Eckerling, B., Zukerman, Z., Mannheimer, S. Blood glucose and plasma insulin levels with ethynodiol diacetate oral contraceptive. J. Obstet. Gynaec. Brit. Cwlth 78, 255-260 (1971)

Received: Iuly 30, 1976, and in revised form: November 8,1976

Prof. Dr. J. A. Goldman

Dept. of Obstetrics-Gynaecology

Hasharon Hospital and

Tel-Aviv Univ. Medical School

Petah-Tikva, Israel 